\title{
AiMT
}

Advances in Military Technology

Vol. 15, No. 2, 2020, pp. 425-434

ISSN 1802-2308, eISSN 2533-4123

DOI 10.3849/aimt.01402

\section{Reliability and Maintainability Requirements for Mobility Means of Surface-to-Air Missile Systems}

\author{
P.V. Open'ko ${ }^{1 *}$, V.V. Tyurin ${ }^{1}$, M.Y. Mironyuk ${ }^{1}$, \\ P.A. Drannyk ${ }^{1}$ and V.V. Kobzev ${ }^{2}$ \\ ${ }^{1}$ National Defense University of Ukraine named after Ivan Cherniakhovskyi, Kyiv, Ukraine \\ ${ }^{2}$ Kharkiv National University named after Ivan Kozhedub Air Force, Ukraine
}

The manuscript was received on 23 March 2020 and was accepted after revision for publication as research paper on 3 November 2020.

\begin{abstract}
:
The article solves the problem of complex substantiation of reliability and maintainability requirements for mobility means of surface-to-air missile (SAM) systems considering hierarchical structure of mentioned systems and appropriate characteristics of their mobility means, minimum configuration of SAM system means for air defense operation and a number of tactical characteristics of operation area. The quantitative characteristics of effectiveness of SAM system mobility means are measured by the coefficient of effectiveness sustainment which is the ratio of initial effect considering reliability and maintainability of mobility means to its value in case of faultless mobility means. The developed mathematical models, which are proposed for further use as a program product, are designed for defining the limit values of such reliability measures as mean range between failures and mean recovery time of combat and technical facilities of SAM system corresponding to given values of coefficient of effectiveness sustainment.
\end{abstract}

\section{Keywords:}

maintainability requirements, mobility means, reliability requirements, surface-to-air missile system

\section{Introduction}

The experience of current warfare testifies the necessity to use joint efforts of all armed struggle assets and forces, as well as their comprehensive use in any geographical conditions. Thus, an enemy's air attack repelling and troops and facilities defense

\footnotetext{
* Corresponding author: Research Department of the Institute of Aviation and Air Defense, National Defense University of Ukraine named after Ivan Cherniakhovskyi, Povitroflotsky Prospect 28, UK 03049 Kyiv, Ukraine.Phone: +38066 764 5920,E-mail: pavel.openko@ukr.net
} 
from air strikes are one of the most important forms in current armed operations structure. The implementation (introducing) of new air attack means into service stimulate increasing mobile SAM systems survivability requirements.

Development of new (modernization of existing) SAM systems [1,2] and organization of combat employment and logistical support of air defense combat units are related to the solution of the following problems. Firstly, it is necessary to substantiate requirements for reliability of their mobility means [3, 4]. And secondly, it is important to take into account the influence of mobility means' reliability level limits on the effectiveness of SAM system combat operation, and on its logistical support.

Considering the fact that in many cases the reliability and maintainability determine the effective functioning and quality of any weapon system [3, 4], the problem of comprehensive substantiation of reliability and maintainability requirements for SAM system mobility means, including their service features, is solved herein.

\section{Problem Formulation}

It is known that during research and design of prospective (modernization of existing) SAM systems, a provided coefficient of effectiveness sustainment is evaluated for substantiation of proposals of mobility means use. Moreover, during surface-to-air missile forces combat employment and logistical planning, the commanders evaluate effectiveness of operations conducting. The evaluation needs consideration of defined initial data, including SAM system means reliability. A considerable number of works have dealt with this problem [5-12], where, unfortunately, the main attention usually paid to the reliability of its ground combat vehicles or radioelectronic equipment provided that SAM system mobility means are reliable or correspond to given probability of successful execution of complex march at a defined distance.

Particularly, different vehicles reliability is considered in the following studies [13-15]. In [16] there has been developed the method for substantiation of requirements to SAM system mobility means reliability. Meanwhile, the method proposed in [16] has some assumptions and limitations, as only one dependability component (reliability) was investigated. Moreover, mobility means were considered as irreparable facilities. Whereas this approach determines mobility mean failure as the final event, the success of task execution depends on a number of failure-proof mobility means. However, in reality, the considered mobility means are repairable. So in order to ensure the adequacy of the calculation results, it is necessary to additionally take into account the probability of successful task completion in the case of repairing the mobility means' up state within a certain specified period.

Moreover, in [16] the effectiveness of SAM mobility means was considered only in view of combat firing support. Meanwhile, according to the experience of recent local conflicts, in case of late evasion, the SAM system will be destroyed with a high probability. While evaluating the SAM system mobility means effectiveness, it is necessary to consider additionally the timeliness of SAM system evasion.

Unfortunately, resolving the problem of evaluation of timely arrival of mobility means to the destination point which ensure the required minimum configuration in defined hierarchical structure (for air defense operation), as well as timely leaving from the destination point at a defined distance, are absent in known sources. There is no comprehensive approach to this issue; only solving particular elements of the mentioned problem can be retrieved in the related literature. 
This article is aimed at developing the method of complex substantiation of reliability and maintainability requirements for mobility means of SAM system considering its hierarchical structure and influence of SAM system mobility means reliability on its effectiveness.

\section{Description of the Method and Basic Mathematical Equations}

It is known that a SAM system is a complex technical object consisting of vehicles of its combat and technical means. It is necessary to evaluate the influence of mobility means on SAM system technical state using the appropriate coefficient of effectiveness sustainment $\left(K_{\text {eff }}\right)$ [16] taking into account the "non-ideality" of these means. $K_{\text {eff }}$ can be represented as follows:

- for SAM system combat means - as a ratio of the mathematical expectation (ME) of the firings that the SAM system will be able to perform, taking into account the combat means delivered to the launching positions, and those who timely left them, to a number of firings which the SAM system, with its full complement, can execute,

- for SAM system technical means - as a ratio of missile number ME which were delivered by vehicles of technical means to launching positions, to the value of missiles stock in technical unit.

In these conditions the values of the mentioned MEs depend on a number of vehicles of combat and technical means, on the number of considered vehicles which functioned without failures or were recovered during appropriate time intervals in combat operation.

All modern and prospective medium- and long- range air defense systems and complexes (PATRIOT, SAMP-T, MEADS, S-400, HQ-22 (FK-3), HQ-9 (FD-2000) etc.) have hierarchical branched structure which was considered in [16]. It is worth using this approach herein because the SAM system functional structure as in [16] is presented by hierarchical branched system [1, 2, 5, 8]. According to it, the structural scheme of the SAM system mobility means consists of three levels. The zero level of the structural scheme corresponds to the vehicle of missile-guidance radar, the first level - the vehicle of launcher coupled with missile launch preparation equipment, and the second level - vehicle of the launcher without missile launch preparation equipment.

In the mentioned system, $n_{k}$ means the quantity of elements of $\mathrm{k}$ level, directly subordinated to one $(k-1)$ level, $N_{k}$ is the total number of $k$ level elements.

However, the established march length for mobility means of SAM system (while taking positions, leaving them, delivering missiles) and the corresponding values of reliability and maintainability measures of mobility means are used as the initial data for the calculation of the coefficient of effectiveness sustainment for SAM systems' combat and technical mobility means during the planning of combat operations and logistical support.

While calculating the coefficient of effectiveness sustainment of SAM mobility means, the possibility of connecting the $2^{\text {nd }}$ level launcher to any of the $1^{\text {st }}$ level launchers is assumed. Also, the number of the $2^{\text {nd }}$ level launchers that can be connected to the $1^{\text {st }}$ level launchers is not limited. This fact indicates that a necessary condition for at least one firing is the timely delivery to launching positions and leaving them:

- zero-level element (missile-guidance radar), 
- at least one element of the $1^{\text {st }}$ level (launcher coupled with missile launch preparation equipment).

Considering the abovementioned, the coefficient of effectiveness sustainment of vehicles of SAM system mobility means $K_{\text {eff cm }}$ can be represented as follows:

$$
K_{\text {eff cm }}=\frac{n_{\text {SAM }}}{N_{\text {SAM }}} \sum_{k=1}^{n_{1}+n_{2}} k P_{0} P_{12}(k)
$$

where $n_{\text {SAM }}$ is the number of missiles on a single launcher; $N_{\text {SAM }}$ is the total number of missiles in the SAM system; $n_{1}, n_{2}$, are the numbers of mobility means of the $1^{\text {st }}$ and the $2^{\text {nd }}$ levels respectively; $P_{0}$ is the probability of being in an up state for the mobility means of the $0^{\text {th }}$ level; $P_{12}(k)$ is the probability of the event that exactly $k$ combat means of the $1^{\text {st }}$ and the $2^{\text {nd }}$ level will be successfully deployed to the firing positions assigned to the SAM system and timely withdrawn by the corresponding mobility means.

The number of SAM system combat means of the $1^{\text {st }}$ and the $2^{\text {nd }}$ level delivered and withdrawn by the mobility means is a random variable and has the binomial distribution $[1,2,7,8]$. Equation for the $P_{12}(k)$ calculation is obtained as the sum of the probabilities of all possible combinations of reliable functioning the $1^{\text {st }}$ and the $2^{\text {nd }}$ level elements, which would provide the required number of combat means of the SAM system which will be delivered and withdrawn by the vehicles.

Considering their hierarchical subordination and the limited number of elements at each level, the probability $P_{12}(k)$ can be represented as follows:

$$
P_{12}(k)=\sum_{i=I_{1}\left(k, n_{2}\right)}^{I_{2}\left(k, n_{1}\right)} C_{n_{1}}^{i} P_{1}^{i}\left(1-P_{1}\right)^{n_{1}-i} C_{n_{2}}^{k-i} P_{2}^{k-i}\left(1-P_{2}\right)^{n_{2}-(k-i)}
$$

where $P_{1}, P_{2}$ are the probabilities of being in the up state of the $1^{\text {st }}$ and the $2^{\text {nd }}$ level elements (mobility means) respectively; $I_{1}\left(k, n_{2}\right), I_{2}\left(k, n_{1}\right)$, are the lower and upper limits of summation respectively, which gives the following values:

$$
I_{1}\left(k, n_{2}\right)=\left\{\begin{array}{ll}
1, & \text { if } k \leq n_{2} ; \\
k-n_{2}, & \text { if } k>n_{2} ;
\end{array} I_{2}\left(k, n_{1}\right)= \begin{cases}k, & \text { if } k \leq n_{1} \\
n_{1}, & \text { if } k>n_{1}\end{cases}\right.
$$

Taking into account Eqs (2) and (3), the coefficient of effectiveness sustainment of SAM system combat means' vehicles can be presented as follows:

$$
K_{\text {eff cm }}=\frac{n_{\mathrm{SAM}}}{N_{\mathrm{SAM}}} \sum_{k=1}^{n_{1}+n_{2}} k P_{0} \sum_{i=I_{1}\left(k, n_{2}\right)}^{I_{2}\left(k, n_{1}\right)} C_{n_{1}}^{i} P_{1}^{i}\left(1-P_{1}\right)^{n_{1}-i} C_{n_{2}}^{k-i} P_{2}^{k-i}\left(1-P_{2}\right)^{n_{2}-(k-i)}
$$

In the Eq. (4) the $P_{0}, P_{1}$ and $P_{2}$ are the product of the corresponding probabilities of delivery of the first level combat means and their withdrawal from positions, which, in turn, are functions of the values of the corresponding reliability and maintainability measures. If the decrease in the reliability of the vehicles of SAM system combat means during the march and the change in their maintainability can be neglected, then we can assume that the vehicles' probability of faultless and the probability of vehicles' recovery are submitted to exponential distribution $[1,2,7,8]$. As a result, the equation for calculating the probability of successful completion of a partial task (delivery, return) by the repairable vehicle of SAM system combat means of the $i^{\text {th }}$ level can be represented as follows: 


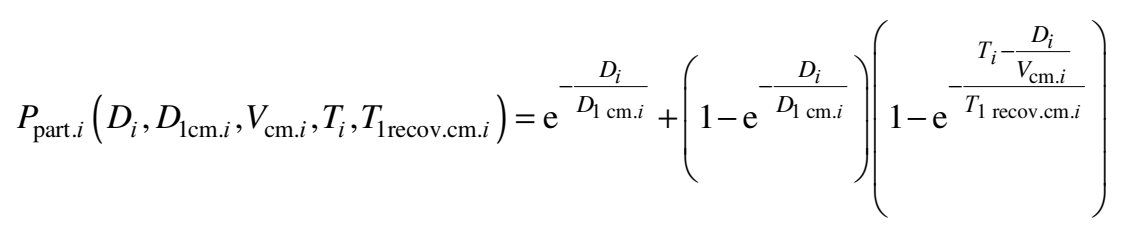

where $D_{i}$ is the distance the combat vehicle of the $i^{\text {th }}$ level must travel (the length of march); $D_{1 \mathrm{~cm} . i}$ is the mean distance before failure (MDBF) of the vehicle of the $i^{\text {th }}$ level combat mean; $T_{i}$ is the time interval allocated to carry out the movement (duration of march) of the $i^{\text {th }}$ level combat mean; $T_{\text {1recov.cm. } i}$ is the mean recovery time of the vehicle of the $i^{\text {th }}$ level combat mean; $V_{1 \mathrm{~cm} . i}$ is the average speed of the $i^{\text {th }}$ level combat means' vehicles.

The probability of delivery by the vehicles of the $i^{\text {th }}$ level of combat means at the position is calculated using equation:

$$
P_{\text {deliv. } i}=P_{\text {part. } i}\left(D_{\text {deliv } . i}, D_{\text {1cm. } . i}, V_{\mathrm{cm} . i}, T_{\text {deliv. } i}, T_{1 \text { recov.cm. } i}\right)
$$

where $D_{\text {deliv. } i}$ is the distance to the positions to which the vehicles of the $i^{\text {th }}$ level combat means are to be delivered (length of march); $T_{\text {deliv. } i}$ is the time interval allocated for delivery by the vehicles of the $i^{\text {th }}$ level combat means (duration of the march).

The probability of withdrawal of $i^{\text {th }}$ level combat means from the position by the vehicles can be calculated using the following equation:

$$
P_{\text {withdr. } i}=P_{\text {part. } i}\left(D_{\text {withdr. } i}, D_{1 \mathrm{~cm} . i}, V_{\mathrm{cm} . i}, T_{\text {withdr. } i}, T_{1 \text { recov.cm } . i}\right)
$$

where $D_{\text {withdr. } i}$ is the distance from the positions to which the vehicle of the $i^{\text {th }}$ level of combat vehicle (length of march) must be brought to; $T_{\text {withdr. } i}$ is the time interval during which it is necessary to bring out the $i^{\text {th }}$ level combat means vehicle (duration of the march).

The probabilities $P_{0}, P_{1}$ and $P_{2}$ from Eq. (4) are calculated as follows:

$$
P_{i}=P_{\text {deliv. } i} P_{\text {withdr. } i}, \quad i=0,1,2
$$

The use of unified mobility means will help to reduce their nomenclature and, accordingly, the cost of the spare parts kits to them. Then in calculations it will be necessary to consider that $D_{1 \mathrm{~cm} .0}=D_{1 \mathrm{~cm} .1}=D_{1 \mathrm{~cm} .2}=D_{1 \mathrm{~cm}}$, $V_{1 \mathrm{~cm} .0}=V_{\text {1cm. } 1}=V_{1 \mathrm{~cm} .2}=V_{\text {1cm }} ; T_{1 \text { recov.cm. } 0}=T_{1 \text { recov.cm. } 1}=T_{\text {1recov.cm. } 2}=T_{1 \text { recov.cm. }}$.

The reduction of average duration of mobility means recovery and the increase of MDBF result in the increase of coefficient of effectiveness sustainment $K_{\text {eff cm }}\left(D_{1 \mathrm{~cm}}, T_{1 \text { recov.cm }}\right)$, which is shown in Fig. 1 . This chart was obtained using the Eqs (4)-(8), for the following input data: the mobility means are uniform, the length of the delivery march at the position $D=50 \mathrm{~km}$; time that is allocated to advance combat means to positions (delivery march duration) $T_{\text {deliv }}=3$ hours; the march length from the positions $D_{\text {withd }}=5 \mathrm{~km}$; the withdrawal march duration $T_{\text {withdr }}=0.3$ hours; the average speed $V_{\mathrm{cm}}=20 \mathrm{~km} / \mathrm{h}$; the number of SAMs on a single launcher $n_{\mathrm{SAM}}=4$; the total number of missiles in SAM system $N_{\mathrm{SAM}}=48$; the number of the mobility means of the $1^{\text {st }}$ and $2^{\text {nd }}$ level $n_{1}=4$ and $n_{2}=8$.

The developed mathematical equations are the basis for the development of the software to be used by commanders and engineers during substantiation of requirements and developing prospective or modernization of existing SAM systems, during evaluation of restrictions caused by current level of reliability and maintainability of 
existing vehicles of SAM system combat means (usually, these restrictions are neglected).

Using the Eqs (4)-(8), the inverse problem can be solved. With a given value of the coefficient of effectiveness, sustainment requirements for the limit values of the reliability and maintainability indices can be determined. For example, when $K_{\text {eff cm }}\left(D_{1 \mathrm{~cm}}\right)=0.9$, depending on the value of $T_{1 \text { recov.cm }}$ we obtain:

$T_{1 \text { recov.cm }}=0.5$ hours, required value $D_{1 \mathrm{~cm} . \text { bound }}=423 \mathrm{~km}$,

$T_{1 \text { recov.cm }}=1$ hour, required value $D_{1 \mathrm{~cm} . \text { bound }}=658 \mathrm{~km}$,

$T_{\text {1recov.cm }}=2$ hours, required value $D_{1 \mathrm{~cm} . \text { bound }}=827 \mathrm{~km}$,

$T_{1 \text { recov.cm }}=4$ hours, required value $D_{1 \mathrm{~cm} . \text { bound }}=929 \mathrm{~km}$.

Thus, the developed models allow to define the limit values of average range between failures and average duration of recovery of SAM system combat vehicles corresponding to the defined values of coefficient of effectiveness sustainment.

If we compare the provided results with those in [16] for similar conditions (950 km, even without consideration of probability of timely position leaving), we can state that due to the reparability requirements, reliability requirements could be reduced. Their interdependence is characterized by inverse correlation corresponding to physical content of considered characteristics.

The coefficient of effectiveness sustainment $K_{\text {eff tm }}$ of mobility means of SAM system technical means is calculated as a ratio of the following values:

- mathematical expectation of missiles quantity to be delivered to launchers by vehicles of technical means and

- stock of SAMs to be transported from technical unit to launchers by vehicles of SAM technical means.

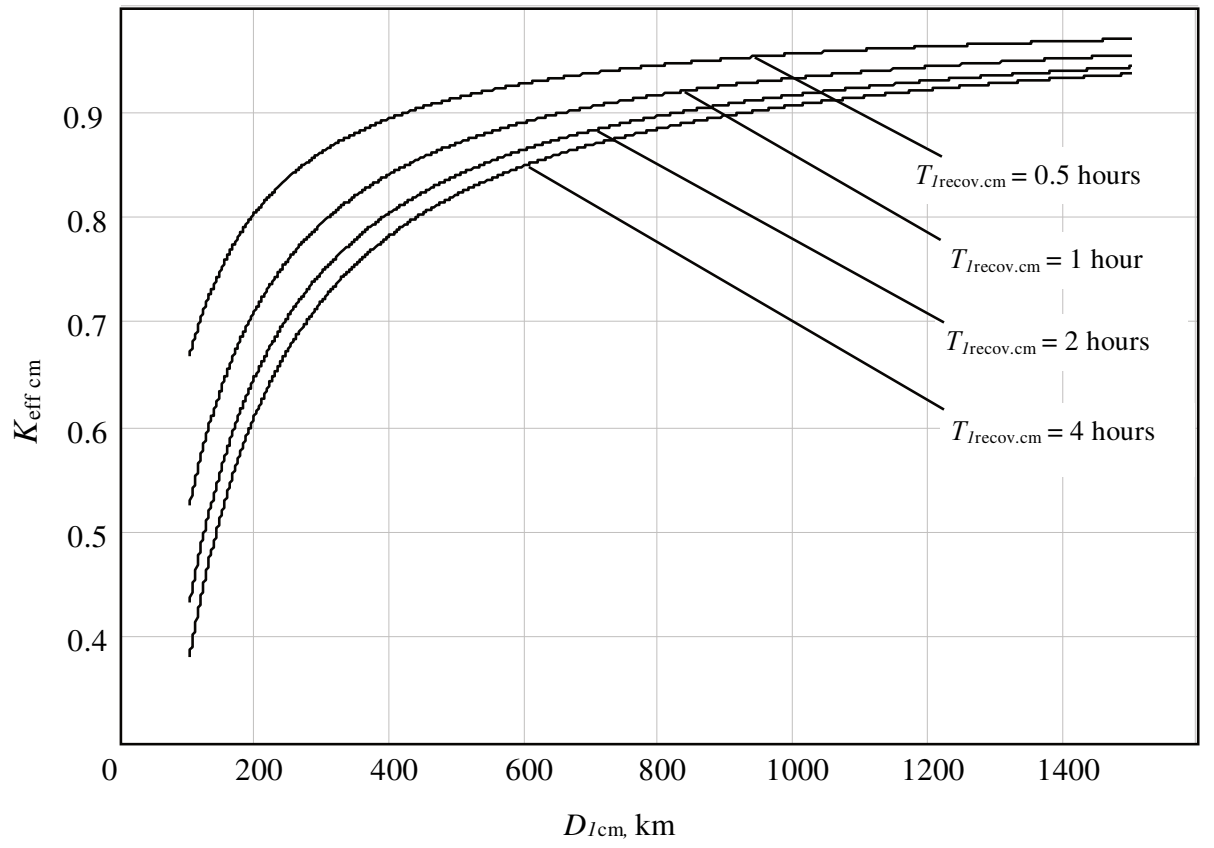

Fig. 1 The dependence of coefficient of effectiveness sustainment of vehicles carrying combat means of SAM system on the value of their MDBF 
While calculating mathematical expectation it is necessary to consider that, generally, the quantity of missiles to be transported is not a multiple of quantity of mobility means, thus, a quantity $m_{1}$ of vehicles of SAM system technical means should execute $r_{1}$ marches, and $m_{2}$ of mobility means $-r_{2}$ marches. Values $m_{1}, m_{2}, r_{1}, r_{2}$ are calculated as follows:

$$
r_{1}=\left[\frac{M_{\mathrm{SAM}}}{m_{\mathrm{SAM}} N_{\mathrm{tm}}}\right], r_{2}=r_{1}+1, m_{2}=\left[\frac{M_{\mathrm{SAM}}}{m_{\mathrm{SAM}}}\right]+1-N_{\mathrm{tm}} r_{1}, m_{1}=N_{\mathrm{tm}}-m_{2}
$$

where $[X]$ denotes the integer part of $X ; M_{\mathrm{SAM}}$ is the number of missiles in the technical unit (arms depot) that are to be carried; $m_{\mathrm{SAM}}$ is the number of missiles that a single technical mobility means of SAM system can carry; $N_{t m}$ is the number of the technical mobility means of SAM system.

The coefficient of effectiveness sustainment $K_{\text {eff tm }}$ for SAM system technical means is calculated as follows:

$$
K_{\text {eff tm }}=\frac{m_{S A M}}{M_{S A M}}\left(m_{1} \sum_{i=1}^{\eta_{1}} P^{i}+m_{2} \sum_{j=1}^{r_{2}} P^{j}\right)
$$

where $P$ is the probability stay of vehicle carrying technical means of SAM system.

The magnitude $P$ is a function of the magnitude of reliability and maintainability. If possible, the decrease in reliability of SAM system technical mobility means during the SAM transportation and changes in maintainability can be neglected $[1,2$, $7,8]$; then we can assume that the ratio for calculating the probability of successful completion of the task by restorative vehicles of technical means of SAM system is similar (5)

$$
P=\mathrm{e}^{-\frac{D_{\mathrm{tm}}}{D_{1 \mathrm{tm}}}}+\left(1-\mathrm{e}^{-\frac{D_{\mathrm{tm}}}{D_{1 \mathrm{tm}}}}\right)\left(1-\mathrm{e}^{-\frac{T_{\mathrm{tm}}-\frac{D_{\mathrm{tm}}}{V_{\mathrm{tm}}}}{T_{1 \text { recov.tm }}}}\right)
$$

where $D_{\mathrm{tm}}$ is the distance to which missiles are to be transported (transportation arm); $D_{1 \mathrm{tm}}$ is the MDBF of technical mobility means; $T_{\mathrm{tm}}$ is the time interval allocated to move the technical mobility means to a distance, which is equal to the value of the transportation arm; $T_{1 \mathrm{tm}}$ is the average duration of recovery of the technical mobility means; $V_{\mathrm{tm}}$ is the average speed of the technical mobility means.

An increase in MDBF of the mobility means and a decrease in the average duration of recovery of the mobility means lead to an increase in the coefficient of

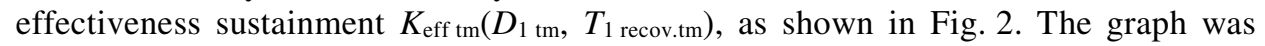
obtained using the Eqs (10) and (11) for the following input data: the distance between the technical unit and the SAM system position; $D_{\mathrm{tm}}=50 \mathrm{~km}$; the time that is allocated to move the technical means of SAM system $T_{\mathrm{tm}}=3$ hours; the average speed of the technical means $V_{\mathrm{tm}}=20 \mathrm{~km} / \mathrm{h}$; the amount of SAMs, that can be transported by one vehicle $m_{\mathrm{SAM}}=2$; the number of missiles in technical unit, that must be delivered to position $M_{\mathrm{SAM}}=50$; the number of technical mobility means $N_{\mathrm{tm}}=12$.

The developed mathematical equations are proposed for the implementation as a software intended for use by the staff of the logistics support of the operational and strategic levels. This software makes it possible to assess the limitations conditioned by the current level of reliability and maintainability of vehicles of existing SAM sys- 
tems (as a rule, these limitations are neglected). Such limitations affect the efficiency of logistical support for combat operations of military units armed with the appropriate air defense systems, in terms of delivery of SAMs.

Using Eqs (10) and (11), the inverse problem is solved. With a given value of the coefficient of effectiveness, sustainment requirements for the limit values of the reliability and maintainability indices are determined. For example, when $K_{\text {eff tm }}=0.8$, depending on the value of $T_{1 \text { recov.tm we get: }}$

$T_{1 \text { recov.tm }}=0.5$ hours, required value $D_{1 \mathrm{tm} . \text { bound }}=110 \mathrm{~km}$,

$T_{1 \text { recov.tm }}=1$ hour, required value $D_{1 \mathrm{tm} . \text { bound }}=199 \mathrm{~km}$,

$T_{1 \text { recov.tm }}=2$ hours, required value $D_{1 \text { tm. bound }}=262 \mathrm{~km}$,

$T_{1 \text { recov.tm }}=4$ hours, required value $D_{1 \mathrm{tm} . \text { bound }}=300 \mathrm{~km}$.

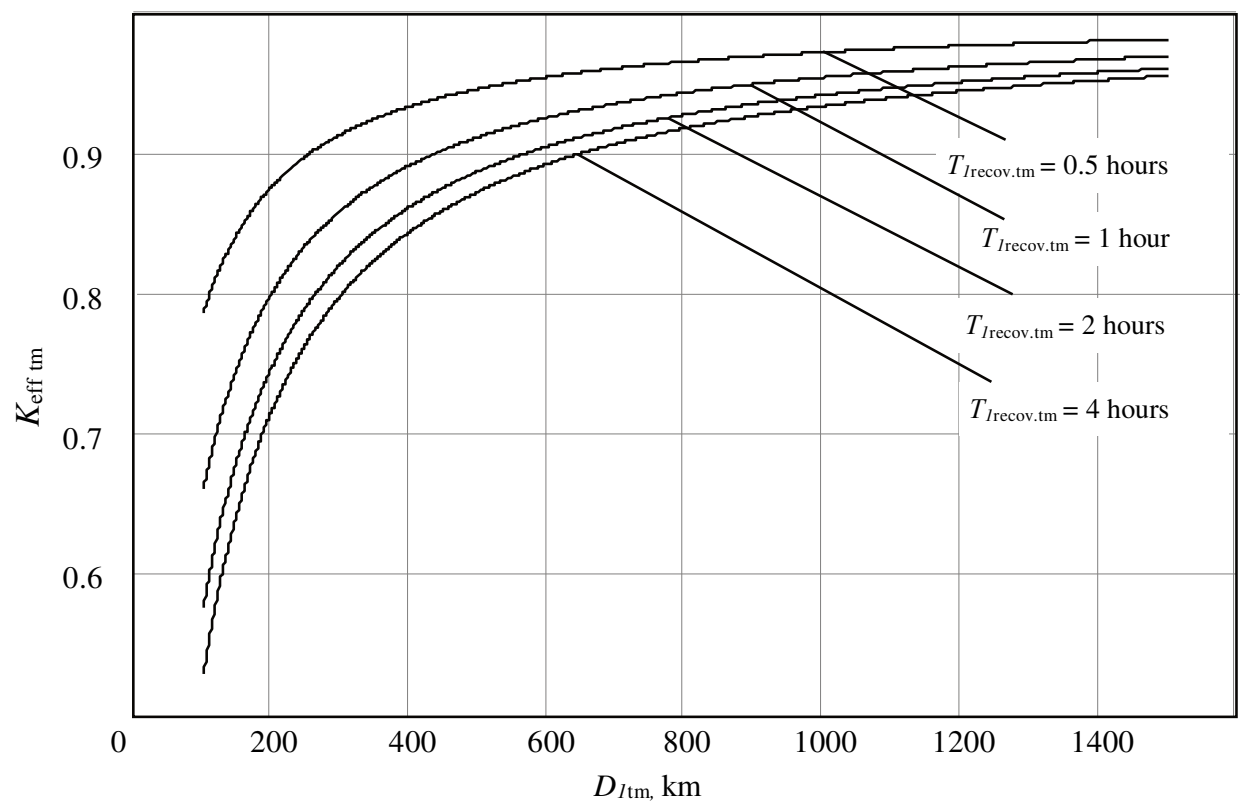

Fig. 2 The dependence of coefficient of effectiveness sustainment of vehicles carrying technical means of SAM system on the value of their MDBF

Thus, the developed models allow to define the limit values of average range between failures and average duration of recovery of SAM system combat vehicles corresponding to defined values of coefficients of effectiveness sustainment.

If we compare the provided results with those in [16] for similar conditions (345 km, even without consideration of probability of timely position leaving), we can state that due to the reparability requirements, reliability requirements could be reduced. Their interdependence is characterized by inverse correlation corresponding to physical content of considered characteristics.

Figs 1 and 2 show that the dependences of coefficients of effectiveness sustainment of SAM combat and technical mobility means are similar (in this case there are power (exponential) dependences). It can be explained by the fact that developed (considering allowances) correlations for calculation of values of the above-mentioned characteristics are functions where the appropriate arguments are within exponential quantities based on the exponential function. The dependences provided on the figures 
are for specific output data which are sufficiently close. They demonstrate that the reliability and maintainability level of SAM combat mobility means influences more the effectiveness value than the values of SAM technical mobility means influence the effectiveness (in case of similar arguments, the graph of dependence of coefficient of effectiveness sustainment of SAM combat mobility means (Fig. 1) is lower than the graph of dependence of coefficient of effectiveness sustainment of SAM technical mobility means (Fig. 2).

\section{Conclusions}

The article has resulted in the development of models for complex substantiating the requirements to SAM system mobility means' reliability components. The requirements are expected to be defined following the evaluation results of reduction of appropriate SAM system effectiveness coefficient calculated considering:

- SAM system hierarchical structure, minimum configuration of SAM system combat and technical means used for air defense,

- complex of tactical characteristics of combat actions area such as march range and duration (missiles delivery), range and required duration of positions leaving,

- technical characteristics of mobility means such as average march speed, capacity to transport missile quantity, reliability and maintainability characteristics.

For some given input values, the proposed mathematical equations were used to obtain coefficients of effectiveness sustainment of vehicles of SAM system combat and technical means as functions of their reliability and maintainability. Commanders and engineers can use the developed equations for similar calculations for other input values received.

The developed models which are proposed as software can be used for defining the limit values of average range between failures and average duration of recovery of SAM system combat vehicles corresponding to defined values of coefficients of effectiveness sustainment.

The developed models have practical importance during both development of prospective and modernization of existing SAM system and SAM system maintenance in military units of air defense forces. Thus, during research and design of prospective and modernization of existing SAM systems these models can be used by scientists and engineers for substantiation of the proposals for use of any mobility means.

While planning combat employment of air defense forces, the developed models can be used by commanders while evaluating the effectiveness of combat operations of military units armed with appropriate SAM systems considering, firstly, the influence of limitations resulted from the reliability and maintainability level of SAM system mobility means and, secondly, the probability of SAMs' necessary stock.

While planning the logistical support of military units of air defense forces, the developed models can be used by operational and strategic logistical commanders to ensure the required level of effectiveness of SAM system combat and technical means.

\section{References}

[1] BOORD, W.J. and HOFFMAN, J.B. Air and Missile Defense Systems Engineering. Boca Raton: CRC Press, 2016. 271 p. ISBN 978-1-4398-0670-5. 
[2] KOVTUNENKO, A.P., ZUBAREV, V.V., LANETSKIY, B.N. and ZVEREV, A.A. Mathematical Modeling in Problems of Research of Reliability of a Technical Systems (In Russian). Kyiv: Knizhkove vidavnitstvo NAU, 2006. 236 p.

[3] ADMP-01:2014, Guidance for Developing Dependability Requirements - Edition A Version 1.

[4] ADMP-02:2014, Guidance for Dependability in-Servise - Edition A Version 1.

[5] GADASIN, V.A. Estimation of the Effectiveness of Hierarchical Systems with Equal Objects with Due Regard for Reliability (in Russian). Izvestiya Akademii Nauk SSSR. Tekhnicheskaya Kibernetika, 1976, no. 6, p. 108-113.

[6] MARTIN P.L. Electronic Failure Analysis Handbook. New York: McGraw-Hill, 1999. 766 p. ISBN 978-0-07-162634-7.

[7] ASH, R.B. Basic Probability Theory. New York: Dover Publications, 2008. 352 p. ISBN 978-0-486-46628-6.

[8] TOBIAS, P.A. and TRINDADE, D.C. Applied Reliability. $3^{\text {rd }}$ ed. Boca Raton: CRC Press, 2011. 600 p. ISBN 978-1-58-488466-8.

[9] OHRING, M. and KASPRZAK, L. Reliability and Failure of Electronic Devices and Materials. $2^{\text {nd }}$ ed. Cambridge: Academic Press, 2014. 758 p. ISBN 978-0-12088574-9.

[10] Military Directives, Handbooks and Standards Related to Reliability [online] [viewed 2019-10-21]. Available from: http://www.weibull.com/knowledge/milhdbk.htm

[11] De AlMEIDA, A.T., CAVALCANTE, C.A.V., ALENCAR, M.H., FERREIRA R.J.P., De ALMEIDA-FILHO, A.T. and GARCEZ, T.V. Multicriteria and Multiobjective Models for Risk, Reliability and Maintenance Decision Analysis. New York: Springer, 2015. 395 p. ISBN 978-3-319-17968-1.

[12] KOBZEV, V.V., OPENKO, P.V. and FOMENKO, D.V. Substantiation of a method of distribution of operational observations on samples at application of a method of group consideration of arguments for forecasting of reliability of radio electronic means of antiaircraft missile complexes (in Ukrainian). Modern information technologies in the field of security and defense, 2012, no. 2(14), p. 3537. - Available from: http://nbuv.gov.ua/UJRN/sitsbo_2012_2_10.

[13] PARKER, S.R. Combat Vehicle Reliability Assessment Simulation Model (CVRASM). In Proceedings of the $23^{\text {rd }}$ Conference on Winter Simulation. Washington: IEEE, 1991, p. 491-498. DOI 10.1109/WSC.1991.185651.

[14] NAIL, M., FENTON, N., FOREY, S. and HARRIS, R. Using Bayesian Belief Networks to Predict the Reliability of Military Vehicles. Computing \& Control Engineering Journal, 2001, vol. 12, no. 1, p. 11-20. DOI 10.1049/cce:20010103.

[15] STRUTT, J.E. and HALL, P.L. Global Vehicle Reliability Prediction and Optimization Techniques. Hoboken: Wiley, 2003. 140 p. ISBN 978-1-86-058368-1.

[16] OPEN'KO, P.V., DRANNYK, P.A., KOBZEV, V.V., BROVKO, M.B. and ZALEVSKY, G.S. Substantiation of Reliability Requirements for Mobility Means of Surface-To-Air Missile Systems. Advances in Military Technology, 2017, vol. 12, no. 1, p. 91-99. DOI 10.3849/aimt.01122. 